\title{
Design and performance of an S-band thulium doped modified silica fiber amplifier
}

\begin{abstract}
A new design of an S-band Thulium-doped modified Silica fiber co-doped with aluminum is presented. The design goal is high gain and low noise figure in the wavelength range of 1450 - $1520 \mathrm{~nm}$. The optimization considers design parameters such as the cut-off wavelength, dopant concentration, waveguide structure, index profile and numerical aperture. These design parameters are optimized to achieve long fluorescence lifetime, high overlap factor and selected mode excitation. The amplifier performance is theoretically modelled and simulated considering the proposed design optimization. We show that the amplifier can achieve a gain of $16 \mathrm{~dB}$ and $3 \mathrm{~dB}$ noise figure.
\end{abstract}

Keyword: Fiber amplifier; S-band optical amplifier; Thulium-doped fiber amplifier (TDFA) 